Yoğun bakımda mekanik ventilasyon uygulanan hastalarda sedasyon ve analjezi

\title{
Sedation and analgesia in patients who need mechanical ventilation in intensive care unit
}

\author{
Özlem Özkan Kuşcu \\ Çukurova Üniversitesi Tıp Fakültesi, Yoğun Bakım Eğitim Programı, Adana, Türkiye \\ Geliş Tarihi: 13.06.2017 Kabul Tarihi: 15.06.2017 Doi: 10.21601/ortadogutipdergisi.321197
}

\section{Öz}

Yoğun bakımda entübe takip edilen hastaların mekanik ventilasyona uyum sağlamaları çoğu zaman medikal destek gerektirir. Uygun sedasyonun uygulanmaması tedavi başarısızlığına neden olur. Bu nedenle yoğun bakım hekimleri sedasyon ve analjezi sağlamak için bazı ajanlara başvurabilirler. Ajanların seçimleri hastanın hemodinamisi, kafa içi basınc1, havayolu dinamikleri, ilacı metabolize edebilme durumu gibi birçok durum göz önünde bulundurularak yapılır. Bu derlemede bu amaçla en sık kullanılan ajanlar ve ajanların tercih edilme ya da edilmeme nedenlerinden bahsedilecektir.

Anahtar Kelimeler: Yoğun bakım, mekanik ventilasyon, sedasyon

\begin{abstract}
Entubated patients in intensive care unit usually needs medical support to be in harmony with mechanical ventilation. Failure to apply proper sedation will result in treatment failure in these patients. For this reason, intensive care physicians may apply to some agents to provide sedation and analgesia. The choice of agents is based on many factors such as the patient's hemodynamics, intracranial pressure, airway dynamics, drug metabolism. In this review, the most commonly used agents for this purpose and the reasons why agents are preferred or not will be mentioned.
\end{abstract}

Keywords: Critical care, mechanicalventilation, sedasyon

\section{Giriş}

Yoğun bakımlarda mekanik ventilasyon uygulanan birçok hasta için sedasyon ve analjezi önemli uygulamalardır. Analjezi ve sedasyon, uygun kullanım ile morbidite ve mortaliteyi azaltır [1]. Ağrı kritik hastalarda sıklıkla tariflenen bir semptomdur. Entübasyon ve mekanik ventilasyon uygulanmasıyla olabileceği gibi rutin hasta bakımı sırasında da ortaya çıkabilir. Hastanın ağrısının ve analjezik ihtiyacının belirlenmesinin en uygun yolu mümkünse hastayla iletişim kurmaktır ve bu nedenle hastaların ko- nuşma veya işaretlemeyle ağrılarını ifade edebilecekleri numerik ölçekler geliştirilmiştir [2]. Sedasyon ve analjezi için geliştirilen bu protokollerin kullanımı ve günlük sedasyon molası ile mekanik ventilasyon ve yoğun bakım yatış süresinin kısaldığı gösterilmiştir [3].

Mekanik ventilasyon uygulanan hastalarda mekanik ventilasyona uyumu arttırmak amaciyla sedatifler, analjezik ajanlar ve nöromusküler blokör ajanlar kullanılır.Bunlardan en sık kullanılanlar Tablo 1'de gösterilmiştir. 


\begin{tabular}{|c|c|c|c|}
\hline \multirow{7}{*}{$\begin{array}{l}\text { SANTRAL SINIIR SİSTEMİ } \\
\text { ÜZERINNDEN ETKİ GÖSTEREN } \\
\text { AJANLAR }\end{array}$} & \multirow[b]{3}{*}{ OPİOİDLER } & Doğal & Morfin \\
\hline & & Yar1 Sentetik & Hidromorfon \\
\hline & & Sentetik & $\begin{array}{l}\text { Fentanil } \\
\text { Alfentanil } \\
\text { Remifentanil }\end{array}$ \\
\hline & \multirow{4}{*}{$\begin{array}{l}\text { NON-OPİOIDLER } \\
\text { (SEDATİF } \\
\text { HIPNOTİKLER) }\end{array}$} & Benzodiazepinler & Midazolam \\
\hline & & Barbitüratlar & Thiopental \\
\hline & & \multicolumn{2}{|l|}{ Propofol } \\
\hline & & \multicolumn{2}{|l|}{ Etomidat } \\
\hline \multirow{3}{*}{ NÖROMUSKULER BLOKÖRAJANLAR } & \multicolumn{2}{|l|}{ DEPOLARIZZAN } & Süksinil kolin \\
\hline & \multirow[t]{2}{*}{ NONDEPOLARIZZAN } & Steroid Yapıl1 & $\begin{array}{l}\text { Veküronyum } \\
\text { bromür } \\
\text { Roküronyum } \\
\text { bromür }\end{array}$ \\
\hline & & Benzilisokinolin Yap1lı & $\begin{array}{l}\text { Atraküryumbesilat } \\
\text { Cisatraküryumbesilat }\end{array}$ \\
\hline
\end{tabular}

A-Santral Sinir Sistemi Üzerinden Etki Gösteren Ajanlar

\section{I-Opioidler}

Opioid ilaçların prototipi morfin, Papaver somniforum (haşhaş) bitkisinden elde edilen beş halkalı alkaloiddir. Santral sinir sistemindeki nöronlarda nöromediyatör olarak görev yapan endojen opioid peptidlerin (endorfin, enkefalin, dinorfin) etkilediği reseptörleri aktive ederler. Böylece endojen opioid peptidleri taklit ederek farmakolojik etkilerini oluştururlar. Opioid analjezikler natürlerine göre doğal, sentetik ve yarı sentetik olarak ayrılırlar. Morfinin beş halkalı iskelet yapısının modifikasyonuyla yarı sentetik opioidler, kaynaşmış halkaların azaltılmasıyla da sentetik opioidler elde edilmiştir. Opioidler güçlü analjezik etki sağlar ancak bağımlılık ve fiziksel yoksunluk yapma potansiyelleri de mevcuttur [4]. Özellikle kısa etkili opioidlere ilaç potensinden bağımsız olarak hızlı tolerans gelişebilir [5]. Mekanik ventilasyon uygulanan entübe hastalarda opioidlerin analjezi ve sedasyon dişında üst ve alt havayolu reflekslerini baskılamaları da başka bir tercih sebebi olabilmektedir [6].

\section{I.1.Doğal Opioid}

\section{I.1. Morfin}

Bilinen en eski opioid analjeziktir. Mü reseptörlerinin santral sinir sistemini etkilemesiyle etki gösterir. İntravenöz yoldan uygulandığında beş dakikada, intramusküler uygulandığında 15 dakikada etkisi başlar. İntravenöz, oral, sublingual, bukkal, rektal,epidural, intratekal uygulanabilir. Solunum depresyonu, hipotansiyon, bradikardi, baş ağrısı, bulant1kusma, görme bozukluğu, konstipasyon, üriner retansiyon, biliyer spazm ve histamin salınımına neden olabilir [7]. Büyük oranda karaciğerde glukuronidasyonla metabolize olur. Ortaya çıkan inaktif metaboliti morfin-3 glukuronid, nöroeksitasyondan sorumludur, aktif metaboliti morfin-6 glukuronid ise morfinden daha güçlüdür, daha uzun eliminasyon ömrü olması geç solunum depresyonunun nedenidir, metabolitler böbreklerden atılır, karaciğer ve böbrek yetmezliğinde doz azaltmak gerekir. Etki süresi 3-7 saattir. Altı saatte bir 4-10 mg (intravenöz) ek doz yapılabilir [8,9].

\section{I.2. Yarı Sentetik Opioid}

\section{I.2.Hidromorfon (Dihidromorfinon)}

Oral ya da sublingual biyoyararlanımı düşük olduğu için genellikle intravenöz yol tercih edilir.

Karaciğerde metabolize olup böbreklerden atılır. Yan etkileri doz ilişkili solunum depresyonu, üriner retansiyon, bronkospazm, hipotansiyon, bulantı-kusma, baş ağrısı, konstipasyon, terleme, halüsinasyon görme bozukluğu hipogonadizm ve özellikle böbrek fonksiyon bozukluğunda daha fazla görülen nöroeksitasyondur [9]. Etki başlangıcı intravenöz uygulandığında 5 dakika, oral uygulandığında 30 dakikadır. 0,5-3 mg/saat ile uygulmaya başlanır, yanıta göre doz titre edilir. Etki süresi 2-3 saattir, böbrek yetmezliğinde 40 saate kadar uzayabilir [10]. 


\section{I.3. Sentetik Opioid}

\section{I.3a.Fentanil}

Sentetik opioiddir, potent, pür mü reseptör agonistidir. Transdermal, intravenöz (bolus/infüzyon), bukkal, intranasal uygulanabilir. \%80-85 proteine bağlanır, karaciğerden CYP3A4 ile metabolize olur. Atılımı \%75 idrar, \%9 feçes ile olur . Solunum depresyonu, kas rijiditesi, allerji, hipotansiyon, bradikardi, bulantı kusma olası yan etkileridir. Morfine oranla daha az histamin salınımına neden olur [11]. Başlangıçta 1-2 mcg/kg intravenöz bolus yükleme dozu yapılıp, $1-2 \mathrm{mcg} / \mathrm{kg} / \mathrm{saat}$ infüzyon ile idame edilebilir. Etkisi intravenöz uygulandığında hemen, intramusküler uygulandığında ise 7-15 dakika sonra başlar, etki süresi 2-4 saattir [12].

Eşdeğerlik:0,1mg/kg morfin=0,001mg/kg Fentanyl $=0,015-0,02$ Hidromorfon [7].

\section{I.3b.Alfentanil}

En kısa etkili sentetik opioiddir. Potensi ve etki süresi fentanilden daha az olmakla birlikte daha hızlı etki başlangıç süresine sahip fentanil derivesidir. Karaciğgerde metabolize edilir. Etki süresi ortalama 15 dakikadır, etki süresinin kısa olması ve yan etkisinin az olması dolayısı ile yoğun bakım hastaları için uygun bir seçenektir. Yükleme dozu 8-20 mcg/ kg'dır, idamesi 0,5-1 mcg/kg/saat şeklinde yapılabilir [13].

\section{I.3c.Remifentanil}

Hızlı etki başlangıcı ve kısa derlenme süresine sahip potent ve pür mü antagonistidir. Hipotansiyon, bradikardi, kas rijiditesi, bulantı, kaşıntı olası yan etkileridir. Remifentanilin hiperaljeziye neden olduğunu gösteren çalışmalar olması dolayısı ile remifentanil kullanılan hastalarda hiperaljezi olasılığı akılda tutulmalıdır [14]. 0,5-1 mcg/ $\mathrm{kg} / \mathrm{dk}$ yükleme dozudur. İdame dozu ise $0,05-2 \mathrm{mcg} / \mathrm{kg} /$ dk'dır, beraberinde kullanılan hipnotiklerle doz azaltılabilir, etki süresi 3-10 dakikadır [15]. Kan ve doku esterazları tarafindan metabolize edilir [16].

\section{Nalokson (Opioid Antagonisti)}

Kompetetif opioid antagonistidir, opioid doz aşımında kullanılır. Morfin, fentanil, alfentanil ve remifentanilin etkilerini kompetetif inhibisyon ile antagonize eder . Taş1kardi, hipotansiyon, hipertansiyon, başağrısı ve akciğer ödemine neden olabilir $[7,17]$. 0,4-2 mg intravenöz, intramusküler ya da subkütan uygulanabilir, hastanın sedasyon durumuna göre 10 mg'a kadar uygulanabilir. Etki süresi 45 dakikadır bu nedenle opioidlerin birikici etkisine karşı infüzyon şeklinde verilmesi gerekebilir [18].

\section{Non-Opioidler (SedatifHipnotikler)}

\section{II.1.Benzodiyazepin}

\section{Il.1.Midazolam}

Anterograd amnezi sağlar. Epileptik nöbet kontrolünde birinci basamak tedavi ajanıdır [19].

Hipotansiyon ve sistemik vasküler dirençte azalma bildirilmiş ancak birçok çalışmada da kardiyovasküler etkilenmenin minimal olduğu gösterilmiştir [20]. İntravenöz 0,01-0,08 mg/ kg 2-3 dakikada uygulanarak sedasyona başlanır, 0.02-0.2 $\mathrm{mg} / \mathrm{kg} /$ saat sürekli infüzyon ile sedasyon idame ettirilir[21].

\section{Flumazenil (BenzodiazepinAntagonisti)}

Kompetetif benzodiazepin antagonisti, benzodiazepinlerin santral sinir sistemi depresyonu etkisini geri çevirir [22]. K1sa etki süresine sahip olması nedeniyle benzodiazepinlerin uzamış etkilerini geri çevirmek için sürekli infüzyon şeklinde uygulama yapmak gerekir. 1-2 dakikada etkisi başlar, 30-45 dakika sürer. 0,2 mg intravenöz uygulanıp, yanıt alınamazsa $3 \mathrm{mg} /$ saat'1 aşmayacak şekilde doz tekrarlanabilir [23].

\section{II.2.Barbitürat}

\section{II.2. Sodyum Tiyopental}

Yoğun bakımda sedasyon amaçlı kullanılabilir. Epileptik nöbet tedavisinde ikinci basamak tedaviye yanıt alınamadığında,anestezikdozda kullanılabileceği, kanıt düzeyi düşük olsa da önerilmektedir [19]. Hipotansiyon, ürtiker, bronkospazm, hipernatremi yapabilir. Porfiri ve alerjik reaksiyon öyküsü olan hastalarda kullanımı kontrendikedir.Tiyopentalin pH'sı 10 iken kas gevşeticiler asit pH'dadır ve aynı hattan infüze edilmeleri çökelti oluşumuna neden olur, bu nedenle birlikte infüzyondan kaçınılmalıdır [24]. İntravenöz 3-5 mg/ $\mathrm{kg}$ bolus indüksiyon dozudur, saatte $1-3 \mathrm{mg} / \mathrm{kg}$ ile etkisi idame ettirilir, birikici etkisi göz önünde bulundurulmalıdır [25].

\section{II.3.Propofol}

Yoğun bakım hastalarında sedasyon ve hipnoz oluşturmak için kullanılır [26]. Anksiyolitik, antikonvülzan, antiemetik ve intrakranyal basıncı düşürücü etkiye sahiptir [27, 28]. Epileptik nöbet tedavisinde ikinci basamak tedaviye yanıt alınamadığında, yeterli kanıt olmasa da anestezik dozda kullanılabileceği belirtilmektedir [19]. Negatif inotrop, kronotrop ve vazodilatör etkileri ile kardiyak outputu azaltır ve ciddi hipotansiyon görülebilir [29]. 
Nadir durumlarda idrar ve tırnak yatağında yeşil renk oluşumuna neden olabilir. Yüksek dozda ( $>83 \mu \mathrm{g} / \mathrm{kg} / \mathrm{dk}$ ) propofol infüzyonu uygulanan olgularda metabolik asidoz, bradiaritmi ve progresif miyokardiyal etkilenmenin olduğu 'Propofol İnfüzyon Sendromu' görülebilir. 48 saatten uzun kullanılan ve vazopresör ihtiyacı olan hastalarda risk daha fazladır [30]. Saklama koşullarına uyulmadığında kolaylıkla süperenfeksiyona neden olabilir [31]. Fosfolipid içermesi nedeniyle hastaya $1,1 \mathrm{kcal} / \mathrm{mL}$ enerji sağlar ve hipertrigliseridemiye neden olabilir[32]. Enjeksiyon alanında yanma ve ağriya neden olabilir. Ciddi kalp yetmezliği, yumurta allerjisi, soya allerjisiolan hastalarda kullanımı kontrendikedir. İntravenöz uygulanır, etki başlangıcı 30-45 saniyedir, ve etkisi 3-10 dakika sürer.Başlangıç dozu 1-2,5 mg/kgintravenözbolus,idamedozu ise $0,020-0,075 \mathrm{mg} / \mathrm{kg} / \mathrm{saattir}$ [33].

\section{II.4.Etomidat}

Etomidat hızlı seri entübasyonda kullanılabilir olması nedeniyle tercih edilebilecek bir ajandır [34]. Hızlı etki başlangıcı ve kısa etki süresine sahip olması önemli bir özelliğidir [35]. En az kardiyak depresyon yapan indüksiyon ajanı olması nedeniyle kardiyopulmoner rezervi kısıtlı hastaların entübasyonunda tercih edilir ancak adrenal yetmezliğe neden olması dolayısı ile entübasyon dışı sedasyon uygulamaları için uygun bir seçenek değildir [36]. Karaciğer ve plazma esterazlarınca metabolize edilir, idrarla atılır. Myoklonik kas spazmlarına ve opistoklonusa neden olabilir. İndüksiyonda 0,3-0,6 mg/kg intravenöz bolus uygulanır, 0.2 ila $0.4 \mathrm{mg} / \mathrm{kg}$ (10-20 mg), dozunda spontan ventilasyon devam eder, 60 saniyede etkisi başlar, 3-5 dakika sürer [37].

\section{B. NöromuskülerBlokör Ajanlar}

Mekanik ventilasyon uygulanan bazı hasta gruplarında nöromusküler blokörler tercih edilir. S1klıkla trakeal entübasyonu kolaylaştırmak için, Akut Respiratuar Distres Sendromu (ARDS) ve status astmatikusta mekanik ventilasyon optimizasyonunu sağlamak için, terapötik hipotermide titremeyi engellemek için ve intrakranyal basıncı yüksek hastalarda basınç kontrolünü sağlamak için kullanılır. $\mathrm{PaO} 2 / \mathrm{FiO} 2$ oran 150 mmHg'nın altında olan ARDS hastalarında erken 48 saatte cisatraküryum ile akciğer mekaniklerin düzeldiği gösterilmiştir [38]. Sonuçların iyileşmesini sağlayan mekanizmalar tam açık olmamakla birlikte mekanik ventilasyonla senkronizasyonun arttığı, daha iyi yapılan recruitmentla komplians, gaz değişimi ve oksijenizasyonun düzeldiği düşünülmektedir. İnspiratuar basınç ve volüm kontrolünün daha iyi sağlanmasıyla atelektotravmave barotravmanın da azalarak pulmoner ve sistemik inflamasyonun azalmasina katkıda bulunduğu tahmin edilmektedir [39]. Status astmatikusu olan hasta grubunda ise sedasyon ve nöromusküler blokör tedavinin interkostal kaslar ve diyafragmayı gevşeterek havayolu basınçlarını düşürdüğü gösterilmiştir [40].

Kas gevşeticiler etki mekanizmasına göredepolarizan ve nondepolarizan olmak üzere iki gruba ayrilır.

\section{B.I Depolarizan Kas Gevşeticiler}

\section{B.I. Süksinil Kolin}

Depolarizasyonla etki gösteren nöromuskuler blokör ajandır [41]. Asetilkolin reseptörüne bağlanarak asetil kolin ve sinaps bağlantısını engellemektedir [42]. Yoğun bakımda hızlı seri entübasyon gibi kısa süreli girişimlerde tercih edilebilir [43], tekrarlayan dozlarda ve hızlı uygulamalarda hiperpotasemiye ve kardiyak disritmiye neden olabilir. $\mathrm{Bu}$ nedenle hasta entübe edildikten sonra kas gevşetici verilmesi gerekiyorsa kürarizasyona nondepolarizan kas gevşetici ile devam edilmelidir. Ailesinde veya kendisinde malign hipertermi öyküsü olan hastalarda, kreatinkinaz yüksekliği olan miyopatilerde, üst motor nöron hasarında, ciddi yanığı olan hastalarda, santral sinir sistemi hasarı nedeniyle iskelet kasında denervasyon gelişmiş hastalarda, penetran göz yaralanması olanlarda kullanımı kontrendikedir. İntravenöz $0,1 \mathrm{mg} / \mathrm{kg}$ dozunda uygulanır, etkisi 0,5-1 dakikada başlar, 9-10 dakikada sonlanır, plazma ve hepatik plazma psödokolinesterazlarınca indirgenir, psödokolinesteraz eksikliği olan hastalarda etki süresi uzar [44, 45].

\section{B.II. Nondepolarizan Kas Gevşeticiler}

Nondepolarizan kas gevşeticiler, asetilkolinle kompetetif inhibisyona girerek nöromusküler blok oluştururlar, etki sürelerine ve kimyasal yapılarına göre sınıflandırılırlar.Yoğun bakımda sıklıkla orta etkili kas gevşeticiler tercih edilir.

\section{B.Il.1.Steroid Yapılı Kas Gevşeticiler}

\section{B.II.1.a.Veküronyum Bromür}

Orta etki süreli, steroid yapılı, nondepolarizan nöroblokör ajandır. Hipersensitivite, kas güçsüzlüğü, uzamış paralizi, kas atrofisi olası yan etkileridir [46]. VeküronyumBromür'e karşı alerji öyküsü olan hastalarda kontrendikedir. Başlan- 
gıçta 0.08 ila $0.1 \mathrm{mg} / \mathrm{kg}$ bolus uygulanır, etki başlangıcı 100-180 saniyedir, $1 \mathrm{mcg} / \mathrm{kg} /$ dakika dozunda idame ettrilir, etki süresi 25-40 dakikadır[47].

\section{B.Il.1.b.Roküronyum Bromür}

Rutin entübasyon ve hızlı seri entübasyon girişimlerinde tercih edilen orta etkili veküronyum derivesi nondepolarizan nöroblokör ajandır [43]. $2^{\circ}$ ila $8^{\circ} \mathrm{C}$ 'de saklanır. Geçici hipotansiyon, hipertansiyon, anaflaksi, rezidüel paralizi, myopati, artmış pulmoner vasküler direnç yapabilir.İndüksiyonda $0.6 \mathrm{mg} / \mathrm{kg}$ yapılır, etki başlangıc1 60-120 saniyedir, hızlı seri entübasyonda $1.2 \mathrm{mg} / \mathrm{kgbolus}$ uygulanır etki başlangıcı 40-70 saniyedir, idamede 10-12 mcg/kg/dakika dozlarında uygulanır. Karaciğer ve böbrek yetmezliğinde doz ayarlamas1 yoktur[48, 49].

\section{Sugammadex (Kas Gevşetici Antagonisti)}

Steroid yapılı nondepolarizan kas gevşeticileri enkapsüle ederek etkilerini antagonize eden modifiyesiklodekstrin türevi ajan[50]. Acil durumlarda $16 \mathrm{mg} / \mathrm{kg}$, derin blokta $4 \mathrm{mg} / \mathrm{kg}$, hafif blokta $2 \mathrm{mg} / \mathrm{kg}$ uygulanır,\%95 metabolize edilmeden idrara atılır. Etki süresi 2 saattir. Ciddi böbrek yetmezliği ve karaciğer yetmezliği olan hastalarda nöromusküler bloğu antagonize eder ancak kullanımının güvenli olduğuna dair henüz yeterli kanıt mevcut değil [51]. Bildirilen yan etkileri arasında sıçrama şeklinde hareketler, ağızda acı, metalik tat, parosmi ve bronkospazm ve nadir alerjik reaksiyonlar bulunmaktadır[52]. Sugammadeks sonras1 nöromuskülerblokaj gerekiyorsa roküronyumun $1,2 \mathrm{mg} / \mathrm{kg}$ kullanılması önerilir ancak veküronyum ile ilgili belirtilmiş doz bulunmamaktadır [51].

\section{B.Il.2. Benzilisokinolin Yapılı Kas Gevşeticiler}

\section{B.Il.2.a.AtraküryumBesilat}

Kompetetif inhibisyonla etki gösteren orta etkili benzilisokinolin türevi nondepolarizan kas gevşeticidir. $0,5 \mathrm{mg} / \mathrm{kg}$ dozuna kadar minimal histamin salınımı görülebilir [53]. Kardiyovasküler sistem üzerine etkisi minimaldir [54]. Hassasiyeti olan hastalarda kullanımı kontredikedir. Böbrek ve karaciğerin atılımdaki rolü minimal olsa da böbrek, karaciğer yetmezliği olan hastalarda uzun süreli infüzyonlarda biriken metaboliti laudanozin kan-beyin bariyerini geçip nöroeksitasyonve nöbete neden olabilir $[55,56] .2^{\circ}$ ila $8^{\circ} \mathrm{C}$ 'de muhafaza edilmelidir[57].İntravenöz0.4-0.5 $\mathrm{mg} / \mathrm{kg}$ bolus ile indüksiyona başlanır, $0.005-0.01 \mathrm{mg} / \mathrm{kg} /$ dakikainfüzyon ile idame ettirilir. Nonspesifikesterazlarca katalize edilir ve organ bağımsızHofmanneliminasyonuylainaktive olur.[58].

\section{B.Il.2.b.CisatraküryumBesilat}

Kompetetif inhibisyonla etki gösteren orta etkili benzilisokinolin türevi nondepolarizan kas gevşeticidir. Atraküryumun cis-enantiomeridir. Nöromusküler bloke edici etkisi atraküryuma göre üç kat daha kuvvetlidir. $2^{\circ}$ ila $8^{\circ} \mathrm{C}$ 'de muhafaza edilmelidir [59]. Eliminasyon için ana yolak Hofmann eliminasyonudur, metabolitlerin \%95'i idrara atılır, böbrek karaciğer yetmezliği olan hastalarda laudanozin gibi toksik metabolitler daha yüksek düzeye ulaşabilir. İndüksiyon dozu $0.15-0.2 \mathrm{mg} / \mathrm{kg}$ iv bolus, $1-2 \mathrm{mcg} /$ $\mathrm{kg} /$ dakika iv infüzyon ile idame ettirilir[60].

\section{Maddi Destek ve Çıkar îlişkisi}

Çalışmayı maddi olarak destekleyen kişi/kuruluş yoktur ve yazarın çıkara dayalı bir ilişkisi yoktur.

\section{References}

1. Walder B, Tramèr MR, Analgesia and sedation in critically ill patients. Sw1ss Med Wkly 2004; 134: 333-46.

2. Novaes A,Aronovih A, Ferraz E, Knobel E. Stressors in ICU: patients' evaluation. Intens Care Med 1997; 23:1282-5.

3. Brattebø G, Hofoss D, Flaatten M, Muri K, Gjerde S, Plsek PE. Effect of a scoring system and protocol for sedation on duration of patients' need for ventilator support in a surgical intensive care unit. Qual Saf Health Care 2004; 13: 203-05.

4. Redmond Jr D, Krystal J. Multiple mechanisms of withdrawal from opioid drugs. Annu Rev Neurosci 1984; 7: 443-78.

5. Cox B, Ginsburg M, Osman O. Acute tolerance to narcotic analgesic drugs in rats. Br J Pharmac Chemother 1968; 33: 245-56.

6. Tagaito $\mathrm{Y}$, Isono $\mathrm{S}$, Nishino $\mathrm{T}$. Upper airway reflexes during a combination of propofol and fentanyl anesthesia. Anesthesiology 1998; 88: 1459-66.

7. Yaster M, Kost-Byerly S, Maxwell LG. Opioid agonists and antagonists. Pain in infants, children, and adolescents. Philadelphia: Lippincott Williams and Wilkins 2003: p. 181-224.

8. drugs.com. Morphine. https://www.drugs.com/morphine.html 2016 [cited 2016 24.11.2016].

9. Smith M. Neuroexcitatory effects of morphine and hydromorphone: evidence implicating the $3 \square$ glucuronide metabolites. Clin Exp Pharmacol Physiol 2000; 27: 524-528. 
10. Hidromorfonn 2016 17.11.2016; Available from: http://reference. medscape.com/drug/ dilaudid-hydromorphone-343313.

11. Mayes S, Ferrone M. Fentanyl HCl Patient-Controlled Iontophoretic Transdermal System for Pain: Pharmacology Ann Pharmacother 2006.

12. Medscape. Fentanyl (Rx). 2016 [cited 2016 17.11.2016]; Available from: http://reference.medscape.com/drug/sublimaze-fentanyl-343311.

13. Bovill JG, Sebel PS, Blackburn CL, Heykants J. The pharmacokinetics of alfentanil (R39209): a new opioid analgesic. Anesthesiology 1982;57: 439-43.

14. Guignard, B, Bossard AE, Carole C, Sessler DI, Lebrault C. Acute Opioid ToleranceIntraoperative Remifentanil Increases Postoperative Pain and Morphine Requirement. Anesthesiology 2000; 93: 409-17.

15. drugs.com. remifentanyl. https://www.drugs.com/dosage/remifentanil.html 2016 [cited 2016 25.11.2016].

16. Dershwitz M, Randel GI, Rosow CE, et al Initial clinical experience with remifentanil, a newopioid metabolized by esterases. Anesth Analg 1995; 81: 619-23.

17. Flacke, J., W. Flacke, G. Williams, Acute pulmonary edema following naloxone reversal of high-dose morphine anesthesia. Anesthesiology 1977; 47: 376-77.

18. Drugs.com. Naloxon. https://www.drugs.com/pro/naloxone.html 2016 [cited 2016 25.11. 2016]

19. Glauser T, Shinnar S, Gloss D, et al. Evidence-based guideline: Treatment of convulsive status epilepticus in children and adults: Report of the guideline committee of the American epilepsy society. Epilepsy Currents 2016; 16: p. 48-61.

20. Sidi A, Rush W. Midazolam's effects on myocardial load and coronary perfusion: Reduced regional O 2 consumption and lactate production during ischemia in dogs. J Cardiothorac Vasc Anesth 1994;8: 302-9.

21. drugs.com. Midazolam. https://www.drugs.com/dosage/midazolam.html 2016 [cited 2016 24.11.2016].

22. Greenblatt D. Sedation: Intravenous benzodiazepines in critical care medicine. The Pharmacologic Approach to the Critically Ill Patient. 3rd ed. Chernow B (Ed). Baltimore, Williams \& Wilkins 1994: p. 321-6.

23. Medscape. Flumazenile. http://reference.medscape.com/drug/romazicon-flumazenil-3437312016 [cited 2016 25.11.2016].

24. Chambi D,Omoigui S. Precipitation of thiopental by some muscle relaxants. Anesth \& Analg 1995;81: 1112.2.

25. Dundee JW, Mccleery WN, Mcloughlın G. The hazard of thiopental anaesthesia in porphyria. Anesth \& Analg 1962; 41: 567-74.
26. Bailie G, Cockshot D, Glew R. Pharmacokinetics of propofol during and after long term continuous infusion for maintenance of sedation in ICU patients. Br J Anaesth 1992; 68: 486-91.

27. Langley MS, Heel RC. Propofol. Drugs 1988; 35: 334-72.

28. Kelly DF, Goodale EB, Herr, Williams J, et al. Propofol in the treatment of moderate and severe head injury: a randomized, prospective double-blinded pilot trial. J Neurosurg 1999;90: 1042-52.

29. Foeex P, Sear J. Cardiovascular effects of propofol. J Drug Development 1991; 4: p. 3.

30. Vasile B, Rasulo F, Candiani A, Latronico N. The pathophysiology of propofol infusion syndrome: a simple name for a complex syndrome. Intensive Care Med 2003;29: 1417-25. Implications for patient care. Eur J Anaesth 2006;23: 990-8.

31. Bennett SN, McNeil MM, Bland LA, et al. Postoperative infections traced to contamination of an intravenous anesthetic, propofol. N Eng J Med 1995;333: 147-54.

32. Carrasco G, Molina R, Costa J, Soler JM, Cabré L. Propofol vs midazolam in short-, medium-, and long-term sedation of critically ill patients. A cost-benefit analysis. CHEST 1993;103: 557-64.

33. Medscape. Propofol. http://reference.medscape.com/drug/diprivan-propofol-343100\#0 2016 [cited 2016 25.11.2016].

34. Smith DC, Bergen JM, Smithline H,Kirschner R. A trial of etomidate for rapid sequence intubation in the emergency department. J Emerg Med, 2000. 18: p. 13-16.

35. Van Hamme MJ, Ghoneim M, Ambre JJ. Pharmacokinetics of etomidate, a new intravenous anesthetic. Anesthesiology, 1978. 49: p. $274-7$.

36. Wagner RL, White PF. Etomidate inhibits adrenocortical function in surgical patients. Anesthesiology, 1984. 61: p. 647-51.

37. Medscape. Etomidat. http://reference.medscape.com/drug/amidate-etomidate-343098\#5 2016 [cited 2016 25.11.2016].

38. Alhazzani W, Alsahrani M, Jaeschke R, et al. Neuromuscular blocking agents in acute respiratory distress syndrome: A systematic review and meta-analysis of randomized controlled trials. Crit Care Med, 2013. 17: p. R43.

39. Forel JM, Rosch A, Marin V, et al. Neuromuscular blocking agents decrease inflammatory response in patients presenting with acute respiratory distress syndrome. Crit Care Med 2006;34: 2749-57.

40. Phipps P, Garrard C. The pulmonary physician in critical care• 12: acute severe asthma in the intensive care unit. Thorax, 2003. 58: p. $81-88$. 
41. Blosser SA, Stauffer JL. Intubation of critically ill patients. Clin Chest Med 1996;17: 355-78.

42. Torda TA, Graham GG, Warwick NR, Donohue P. Pharmacokinetics and pharmacodynamics of suxamethonium. Anaesth Intensive Care 1997;25: 272-8.

43. Perry JJ, Lee j, Wells G. Rocuronium versus succinylcholine for rapid sequence induction intubation. Cochrane Database Syst Rev 2008. 2.

44. Drugs.com. succinylcholine. https://www.drugs.com/monograph/ succinylcholine-chloride.html 2016 [cited 2016 24.11.2016].

45. Orebaugh SL. Succinylcholine: adverse effects and alternatives in emergency medicine. The American journal of emergency medicine, 1999. 17: p. 715-21.

46. Kupfer Y, Namba T, Kaldawi E, Tessler S. Prolonged weakness after long-term infusion of vecuronium bromide. Ann Intern Med 1992;117: 484-6.

47. Drugs.com. Vecuronium. https://www.drugs.com/pro/vecuronium.html 2016 [cited 2016 24.11.2016].

48. Drugs.com. Rocuronium. https://www.drugs.com/pro/rocuronium-bromide-injection.html 2016 [cited 2016 24.11.2016].

49. Khuenl-Brady KS, Pomaroli A, Pühringer F, Mitterschiffthaler G, Koller J. The use of rocuronium (ORG 9426) in patients with chronic renal failure. Anaesthesia 1993; 48: 873-5.

50. Bom A, Bradley M, Cameron K, et al. A novel concept of reversing neuromuscular block: chemical encapsulation of rocuronium bromide by a cyclodextrin $\square$ based synthetic host.Angew Chem Int Ed Engl 2002; 114: 275-80.

51. Drugs.com. Sugammadeks. https://www.drugs.com/ppa/sugammadex.html 2016 [cited 2016.

52. Partownavid P, Bryan R, Willy C, et al. Sugammadex: a comprehensive review of the published human science, including renal studies. Am J Ther 2015;22: 298-317.
53. Lindena G, Arnau H, Liefhold J. Hydromorphon-pharmakologische Eigenschaften und therapeutische Wirksamkeit. Der Schmerz 1998; 12: p. 195-204.

54. Hilgenberg J, Stoelting R, and Harris W. Haemodynamic effects of atracurium during enflurane-nitrous oxide anaesthesia. Brit $\mathrm{J}$ Anaesth 1983;55: 81S.

55. Fodale V and Santamaria L. Laudanosine, an atracurium and cisatracurium metabolite. Eur J Anaesthesiol 2002;19: 466-73

56. Smith CE, van Miert MM, Parker CJ, Hunter JM. A comparison of the infusion pharmacokinetics and pharmacodynamics of cisatracurium, the $1 \mathrm{R} \square$ cis $1^{\prime} \mathrm{R} \square$ cis isomer of atracurium, with atracurium besylate in healthy patients. Anaesthesia 1997;52: 833-41.

57. Pramar Y, Loucas V, Word D. Chemical stability and adsorption of atracurium besylate injections in disposable plastic syringes. Journal of clinical pharmacy and therapeutics, 1996. 21: p. 173-175.

58. Medscape. Atracurium. http://reference.medscape.com/drug/atracurium-343103\#0 2016 [cited 2016 24.11.2016].

59. Pignard J, Bourdeaux D, Kauffmann S, Constantin JM, Sautou V. Physicochemical stability study of injectable solutions of cisatracurium besilate in clinical conditions. Ann Fr Anesth Rean 2014;33: 304-309

60. Medscape. Cisatracurium. 2016 [cited 2016 24.11.2016].

Sorumlu Yazar: Özlem Özkan Kuşçu, Çukurova Üniversitesi Tıp Fakültesi, Balcalı Hastanesi, Yoğun Bakım Ünitesi, Sarıçam, Adana, Türkiye

Email: ozlemozkankuscu@gmail.com 